\title{
By-product Extraction of a Rationality-based Agency Conflict Index from Selected Credit Unions in Kenya: Introducing the Agency Conflict Discriminant
}

\section{Stanley K Kirika*}

Jomo Kenyatta University of Agriculture and Technology, Nairobi, Kenya

\begin{abstract}
For ages, there has not been a mathematical model that measures agency conflict. While all and sundry agree that there may not exist business activities without the concept of agency, little on development of a standard measure of the same has been achieved. This study attempts to develop a quantitative model for agency conflict measurement by utilizing entropy-q rationality model using data from select credit unions in Kenya. Analysis of 47 members and 14 management staff of Stima credit union, 133 members and 16 management staff of Unitas credit union, and 91 members and 16 management staff of Mwalimu National credit union showed overall existence of agency conflict as indicated by the negative value of the rationality difference. The conflict was more severe in Mwalimu National credit union. However, Stima credit union posted a positive agency conflict of $20.64 \%$; on which basis, the regulator may set an appropriate index for the sector financial performance monitoring.
\end{abstract}

Keywords: Entropy-q rationality model; Corporate integrity; Positive and negative agency conflict; Severity

\section{Introduction}

Agency theory is a centuries old theory. When it was posited that managers of other people's money cannot guard it with the same zeal as when it was their own, this has over the years been proven right [1]. But the modern agency theory advances that the principal-agent relationship should reflect efficient distribution of risk bearing costs between the parties [2]. Such a claim certainly ignores two key aspects. First, modern agency theorists assume that after proper information dissemination and allocation of risk bearing costs, the conflict disappears. Secondly, they assume that at all times the appointed agent has the ability to steward the business concern to create wealth perpetually or at least at the required return by the principal.

The initial agency problem emerges when the agent assumes more than the contractual risk $[3,4]$. A secondary problem arises when the agent feels that they are not equitably compensated for their risks; resulting in self-interested behaviour at the expense of the principal. This she does and avoids or makes it difficult for the principal to track information about the entity creating information asymmetry [3], leading to monitoring agent behaviour problem [5]. To alleviate the agency monitoring problem, corporate governance measures are usually developed to help synchronize risk and track the agent's behaviour alluding to the positivist perspective of the agency problem. This study that falls under quantitative behavioural finance attempts to quantify agency conflict which has largely featured in descriptive form over the ages. The proposed agency conflict discriminant is expected to provide information for use by stakeholders to revise or adjust their stakes in an agency contract.

A study conducted in Ghana on agency theoretic determinants of debt levels confirmed that managerial ownership is negatively related to debt level; that the greater the proportion of SME shareholders in management, the lower the debt capital levels were invited to reduce chances of insolvency [6]. This study depicts a management that if none of the managers was a shareholder, they would not bother whether to engage more or less debt; not because they are not aware of the dangers of higher leverage, but possibly choose a route that gives them least stressor that meets individual objectives divergent from the owners'. This alludes to a choice of a mediocre rationality level of managerial financial decision making just because they do not own the entity. Another analysis made on investment stopping times preferences between the investor and the manager, the study finds that by reason of the investor pursuing a risk minimization objective within the investment horizon, the manager on the other hand pursues an early reputation entrenchment in her own favour [4]. This escalates the agency conflict.

However, sometimes managers do not pursue self-interest intentionally. They are often victims of bounded rationality occasioned by information asymmetry and cognitive process inadequacy [7]. But early scholars failed to fully explore the difficulty posed by bounded rationality for organizations [3]. This paper is anchored on bounded rationality, where the operational rationality bounds were estimated using entropy-q rationality model proposed by Kirika in 2016 [8]. Moreover, a study of 12, 449 Taiwanese firms between 1998 to 2011 on the role of auditor in agency conflict and corporate governance in 2014 found out that the auditor played a complementary role in low and medium agency conflict level firms, where corporate governance indicators were used to measure agency conflict [9]. From this study, the use of corporate governance indicators was admirable and reasonable. However, while in agreement with the results, it is possible for agency conflict to exist even when corporate governance is airtight, particularly when the economic rationality of the agent is lower than that of the principal. The sections following include a review of bounded rationality [7] and cumulative prospect theory [10] and corporate integrity [11].

*Corresponding author: Stanley K Kirika, Jomo Kenyatta University of Agriculture and Technology, P.O. Box 0722276580 - 00100 Nairobi, Kenya, Tel: 0722-276580; E-mail: stanleykirika@gmail.com

Received July 03, 2017; Accepted July 27, 2017; Published August 07, 2017

Citation: Kirika SK (2017) By-product Extraction of a Rationality-based Agency Conflict Index from Selected Credit Unions in Kenya: Introducing the Agency Conflict Discriminant. J Bus Fin Aff 6: 279. doi: 10.4172/2167-0234.1000279

Copyright: (c) 2017 Kirika SK. This is an open-access article distributed under the terms of the Creative Commons Attribution License, which permits unrestricted use, distribution, and reproduction in any medium, provided the original author and source are credited. 


\section{Statement of the problem and objectives}

Corporate governance indicators measure how well a firm executes it functions to the satisfaction of the stakeholders. But before getting corporate, humans are individuals first characterized by unique traits, inclinations, idiosyncrasies and hence decision making patterns. Empirical studies on agency theory are hinged on development of measuring scale [12,13], followed by Churchill's procedure [14]. What goes conspicuously missing is a mathematical model, an equivalent of Baumol's cash model, Gordon's growth model and the like, which a user needs to plug in specific pieces of information to generate a result. This result may then be interpreted within a ranking to facilitate decision making. Such a model is likely to afford comparability to the decision maker, and greater levels of generalizability.

Cognizant that agency conflict is primarily associated the conduct of humans towards fulfillment of certain obligations to one another; it is necessary to note that this conduct may be viewed to be dictated by four distinct aspects; willingness, ability, individual assessment biases and the circumstances. Circumstance, in law, serves as the justification of the option for renegotiation as one way of discharging a contract, also referred to as agreement, to address circumstances beyond the control of the agent. Let us give the first three a closer look. In a study done in 2015 on an agency theory scale for financial services, out of the 28 items developed for response, 14 related to willingness of the salesperson (agent) to serve the customer (principal) the way she (principal) wanted [15]. A paltry 5 items addressed the ability of the salesperson to deliver to expectations of the customer. No item addressed the inherent biases in the responses, nor were there any addressing circumstances. The biases referred to here, relate to individual perceptions of value of money and the principal's relationship with their financial resources. Is it possible that some of the negative responses about willingness of the agent to act in the interest of the principal were occasioned by circumstances beyond their control or even customer assessment biases? In general, $32 \%$ of all the items did not address the aspects of individual biases and circumstances which are crucial to the reliability of the study. To address these anomalies, this paper tackled three objectives. First, to review the foundational entropy-q rationality model [8] on which the agency conflict discriminant is anchored and is to be extracted, second, to provide an argument for the relevance of corporate integrity (for firms) and personal integrity (for individuals) as an imperative for agency conflict and hence an integral component of the discriminant and finally, to derive the discriminant and use it to derive discriminants for the unions.

\section{Literature Review}

Many reasons may be attributed to emergence of a principal agent relationship. Among them is the need to invest in a venture that gives a desirable return, which the investor cannot manage on their own or that the investor is engaged in other businesses or employments hence has a higher opportunity cost of time than the agent [16]. Virtually, no business can ever take place without the concept of agency. In general delegation confers operational efficiencies. In this regard, the key focus of related literature has been how to design monitoring and incentive schemes for especially the agent to enable realization of the efficiencies [17]. Further, it has been argued that delegation avoids guilt and responsibility where the principal needs to achieve unethical but legal objectives like laying off staff. This paper reviews two theories that deal with rationality with a view to mapping their effects in the conventional principal agent relationship.

\section{Theory}

\section{Bounded rationality theory}

This theory agreeably advances that the individual human rationality is limited by reason of inadequate cognitive ability to process available information about a decision. Besides, human beings are not accessible to all required information about a decision [7]. Simon coined the term "satisficing" to refer to a subjectively acceptable level of economic decision making rationality from the decision maker's perspective. The theory purports to "provide a starting point for economic theory that deals with the areas of neglect without negating those findings of classical theory that have a good basis in empirical evidence" [7]. The missing link in this theory is the exact measure or extent to which an economic agent rationalizes their decisions. This was described in terms of its opposite as Bayesian incompleteness [18] and base rate neglect $[19,20]$. Credit union members subscribe to the union membership by reason of belief that the union management has the will and ability to generate the desirable return to the member. However, the member does not track the day to day running of the union which creates a possibility of not achieving the return. Moreover, since wealth generation is achieved through the quality of financial decision making by the union's human resource, the member has no direct control of the quality of the human resource hired by management.

On assessing oneself, a person may decide to invest their money in entities run by persons other than themselves even if they had time to run their own entities. The results of the assessment are likely to be that agents are better in economies of scale, are better in consumption, and investment decisions that maximize the principal's wealth according to the super-ordinate goal of a firm. For small and medium enterprises in Kenya, investments earnings go towards supplementing their meager earnings to access a decent living. In particular, people save in credit unions to access periodic credit to send their kids to school when schools open after long holidays or are due to join the next level of education. With the glaring risk that the required return may not be forthcoming, a member needs to determine the risk of inadequate stewardship of her deposits in the credit union by determining financial decision making rationality bounds of the agent (management) as compared to her desired rationality bounds that guarantees her return.

\section{Cumulative prospect theory}

This theory advanced that a financial decision maker under risk prospects to experience higher suffering for a given monetary loss than the associated pleasure for a similar magnitude of gain. This phenomenon is known as loss aversion [10]. Additionally, a decision maker uses subjective weights (probabilities) whereby higher probabilities of gain are under weighted while lower probabilities of gain are over weighted. This happens according to equation 1.

$$
p_{S}=\frac{p_{o} \delta}{\left\{p_{o} \delta+\left(1-p_{o}\right)^{\delta}\right\}^{1 / \delta}}
$$

In this case, $p$ is the subjective probability, $p$ is the objective probability and $\delta$ is the optimism coefficient $(0.61<\delta<0.69)$. The decision maker prioritizes their decision on the basis of the product of the perceived gain and their subjective likelihoods of gain. This relationship was confirmed by Gonzalez and Wu [21]; Abdellaoui [22]; Bruhin et al. [23]. Prospect theory was found to have motivated earnings management across Malaysian industries [24]. In the study from which the agency conflict discriminant was extracted, the function had been used to transform subjective probabilities to objective probabilities. 
This takes care of inherent individual biases as a function of individual levels of optimism or pessimism.

\section{Methodology}

Data was collected from three Kenyan credit unions' - Unitas, Stima and Mwalimu National members and managements for years 2005 and 2015. From Unitas, responses from 133 members and 16 from management staffs was collected. Also, from Stima, responses from 47 members and 14 management staffs were collected. Finally, 91 and 16 responses from members and management respectively were collected from Mwalimu National credit union. Respondents' ages ranged between 22 and 57 years. The key questions were their likelihoods of making a rational financial decision in 2005(r) and 2015( $\Gamma)$, the likelihood of benefitting from an irrational financial decision (q) and that of benefitting from a rational decision (p). Both groups were also required to assess their pessimism or optimism levels by responding to Scheier's Life Orientation Test - Revised. The optimism coefficient was used to develop the relevant decision weights function for transformation of subjective probabilities to objective ones. Finally, each group was to estimate their annual net assets for years 2005 through 2015. The assets data was used to estimate their mean return on assets and volatility of the mean return on assets over the period.

The data was fitted into a Multi-period Bayesian decision model in equation 2 to establish $\mathrm{i}$ and $\mathrm{d}$ (updating decision points) through iteration on a spreadsheet; where $\mathrm{i}$ and $\mathrm{d}$ are the respective numbers of wealth increases and decreases within the 10 year period. Optimism coefficient $\delta$ was found to be 0.632 .

$$
\Gamma=\frac{r p^{i}(1-p)^{d}}{r p^{i}(1-p)^{d}+(1-r) q^{i}(1-q)^{d}}
$$

A geometric Brownian motion model algorithm in $\mathrm{R}$ - program was developed to test whether, using the mean return on assets (drift) and standard deviation (volatility) worked out from the data, similar numbers of increases and decreases would be found. Equation 3 represents a discrete form equation of an Ito process; a special form of a geometric Brownian motion model, that was used. This was determined by altering the number of simulations (reducing) from would be convergence of a wealth diffusion sample path, until the iterated number of decreases was obtained.

Findings showed that a higher number of decision points were needed to avail the number of decreases required. A summary of the extra decision points required is shown in Table 1. For instance, all credit unions members in row 1 needed 11 decision points but posted 18 of them.
The proportion of total required decision points as a fraction of total simulated decision points is referred to as updating consistency rate indicated on the last column. The difference between Total simulated decision points and total required updating decision points is known as ordinary decision points. These represent decisions that were made without reference to previous learning - made by rules of thumb also known as heuristics. Updating consistency rate c, affected the multi-period Bayesian model to be revised to include it in the final model in equation 3 .

$$
\Gamma=\frac{c r p^{i}(1-p)^{d}}{r p^{i}(1-p)^{d}+(1-r) \mathrm{q}^{i}(1-q)^{d}}
$$

This final model was tested and found to generate a positive linear relationship with the wealth turnover over the period under investigation, posting a correlation of 0.884 , an $\mathrm{R}^{2}=0.783$ and an adjusted $\mathrm{R}^{2}$ of 0.751 consistent with recommendations of social science research of between 0.7 and $0.9[25,26]$. Applying the formula to all the groups yielded (Table 2). The table includes education indices deduced from respondents. It is apparent that education correlates positively with entropy (0.941), which measures the potential of quality decision making of a union member [27]. Unfortunately, more educated members are not more rational. Infact, the study indicates a correlation of -0.447 , though not significant at $5 \%$ SL. Besides, declared rationality levels for 2005 and 2015 bear little correlation with actual rationalities, more importantly, negatively correlated at -0.203 . The agency conflict discriminant was then extracted from entropy-q rationality model as a by-product (Table 2 ).

More surprising is that Unitas members (who are least educated) are more rational $(76.34 \%)$ than the stewards of their money $(69.59 \%)$. Likewise, Mwalimu National members are more rational (66.18\%) than their union management $(56.20 \%)$. Only Stima union management operate at a higher rationality (68.51\%) compared to their members (61.59\%). The weighted average of union member rationality is $70.37 \%$ compared to $64.60 \%$ for union managements. Assuming that union members expect their managements to operate at $70.37 \%$ rationality level, it is definite that agency conflict certainly exists, notwithstanding that the three credit unions possess a higher rationality limit than their members as represented by updating consistency rate (UCR) column. An important note is that in the same research [8], it was discovered that there exists a linear functional relationship between operational rationality and return on assets. This means that for every level of rationality exercised there is a corresponding level of return generated by that ability. These results are shown on Table 3 .

\section{Corporate integrity}

\begin{tabular}{|c|c|c|c|c|c|c|c|c|c|}
\hline \multirow[t]{3}{*}{ Credit Union Group } & \multirow{2}{*}{\multicolumn{3}{|c|}{$\begin{array}{c}\text { Required updating decision points } \\
\text { (Rational decisions) }\end{array}$}} & \multicolumn{5}{|c|}{ Simulated Actual decision points } & \multirow[t]{3}{*}{ Updating consistency rate } \\
\hline & & & & \multicolumn{2}{|c|}{ Rational decisions } & \multicolumn{2}{|c|}{ Irrational decisions } & \multirow[b]{2}{*}{ Total } & \\
\hline & Inc & Dec & Total & Inc & Dec & Inc & Dec & & \\
\hline All & 8 & 3 & 11 & 8 & 3 & 7 & 0 & 18 & 0.6111 \\
\hline Females & 7 & 2 & 9 & 7 & 2 & 6 & 0 & 15 & 0.6000 \\
\hline Males & 9 & 4 & 13 & 9 & 4 & 7 & 0 & 20 & 0.6500 \\
\hline Unitas M & 10 & 2 & 12 & 10 & 2 & 3 & 0 & 15 & 0.8000 \\
\hline Stima M & 14 & 5 & 19 & 14 & 5 & 10 & 1 & 30 & 0.6333 \\
\hline Mwal. M & 11 & 3 & 14 & 11 & 3 & 6 & 0 & 20 & 0.7000 \\
\hline U.Mgt & 12 & 1 & 13 & 12 & 1 & 2 & 0 & 15 & 0.8667 \\
\hline S.Mgt & 15 & 3 & 18 & 15 & 3 & 6 & 0 & 24 & 0.7500 \\
\hline M.Mgt & 9 & 2 & 11 & 9 & 2 & 4 & 0 & 15 & 0.7333 \\
\hline
\end{tabular}

Integrity refers to strict adherence to a moral code. This should

Table 1: Required and simulated decision points yielding ordinary decision points. 


\begin{tabular}{|c|c|c|c|c|c|c|c|c|c|}
\hline Credit Union & Entropy & Educ & Rat 2005 & Rat 2015 & Updating times & drift (ROA) & Std dev & UCR & Actual Rat \\
\hline U.mem & 0.1563 & 1.28 & 0.8576 & 0.9665 & 12 & 0.2889 & 0.4604 & 0.80 & $76.34 \%$ \\
\hline U.mgt & 0.1105 & & 0.5592 & 0.8934 & 13 & 0.2735 & 0.0903 & 0.87 & $69.59 \%$ \\
\hline S.mem & 0.2723 & 2.26 & 0.8800 & 0.9699 & 19 & 0.2814 & 0.2579 & 0.63 & $61.59 \%$ \\
\hline S.mgt & 0.5606 & & 0.6866 & 0.9361 & 18 & 0.3208 & 0.2304 & 0.75 & $68.51 \%$ \\
\hline M.mem & 0.4562 & 3.19 & 0.7971 & 0.9808 & 14 & 0.1505 & 0.2330 & 0.70 & $66.18 \%$ \\
\hline M.mgt & 0.2974 & & 0.8173 & 0.8769 & 11 & 0.154 & 0.1646 & 0.73 & $56.20 \%$ \\
\hline
\end{tabular}

UCR: Updating Consistency Rate; Stddev; volatility; Educ: 1-5 increasing education level.

Table 2: Declared and actual financial decision making rationality over the period 2005-2015.

\begin{tabular}{|c|c|c|c|c|}
\hline SACCO Group & Initial wealth (a)KES'000 & Current wealth (b)KES'000 & Wealth Turnover (b)/(a) & Average Rationality \\
\hline Unitas Members & 140 & 2,000 & 0.7634 \\
\hline Unitas Mgt & 827,386 & $9,286,191$ & 11.22 \\
\hline Stima Members & 320 & 2,667 & 8.6959 \\
\hline Stima Mgt & 23,209 & 262,500 & 11.31 \\
\hline M.N. Members & 350 & 2,167 & 0.6159 \\
\hline Mwalimu N. Mgt & $8,073,526$ & $32,500,000$ & 0.6851 & 0.19 \\
\hline
\end{tabular}

Table 3: Effect of average rationality on wealth turnover.

be reflected in transparent and complete harmony in what one thinks declares and does [28]. This meaning may be extended to cover corporate entities and systems. Notably, presence or lack of it is directly associated with human action, driven by aspects like culture corporate [29] or otherwise, as well as the individual's sense of right or wrong. A report on corporate governance and business integrity indicates that $80 \%$ of respondents opined that their corporate board was strongly involved in the design and implementation of the company's integrity policy after the global financial crisis of 2007/2008. Surprisingly, $60 \%$ of the respondents agreed that their company looks at the increased integrity budget (25\%-50\%) as an investment rather than an expense [30]. This paper argues that even after the agent possessing a much higher rationality level than the principal thereby holding the key to manipulation of the agent, she still may choose not to exercise it depending on the level of integrity she employs. The report recons that firms and their stakeholders are gradually recognizing that value in the business and values of the business are grossly related; and that the determinants of growth are also increasingly emanating from nonfinancial assets, although financial performance is still important [30].

This digression underscores the importance of personal and corporate integrity in business. Integrity relates to the willingness to carry out contractual obligations on the part of the agent but of course not the ability; ordinarily, like in credit unions where management is appointed by members, ability is presumed. But circumstance, as argued before is covered by way of disclosure. If the agent makes a lot more than the contractual obligation, it should be dutiful of them to disclose the same to the principal to provide a platform for mutual agreement on the pay-offs to both parties forthwith. Towards the end of crafting a model that measures agency conflict in line with the above arguments, it becomes important to define agency conflict for purposes of the model to be developed. Now that an agent need not engage in acts that may conflict the wishes of the principal, corporate integrity on the part of credit union management is the key driver. Then, in case union managements exercise lower financial decision making rationality than the required by the principal (union member), it is clear that agency conflict will have no doubt have occurred regardless of the measure of integrity employed. This is because; from entropy-q rationality theory every level of rationality is associated with a given level of return on assets. Therefore management must engage a rationality level that guarantees the required return by the principal.
We then define $\Gamma_{\mathrm{p}}$ as the required rationality by the principal to guarantee her required return; $\Gamma_{\mathrm{A}}$ as the rationality level which the agent is exercising in the administration of the principal' investments and $\Phi_{\mathrm{A}}$ as the upper rationality bound that the agent may exercise. We also define $\rho$ as the level of integrity exercised by the agent, and finally $\Psi$ as the probability of occurrence of an agency conflict.

$$
\begin{aligned}
& \Psi=\left\{\begin{array}{lll}
\frac{\left(\Gamma_{\mathrm{A}}-\Gamma_{\mathrm{P}}\right)(1-\rho)}{\Phi_{\mathrm{A}}-\Gamma_{\mathrm{P}}}, & \forall & \Gamma_{\mathrm{A}} \geq \Gamma_{\mathrm{P}} \\
1 & , \forall & \Gamma_{\mathrm{A}}<\Gamma_{\mathrm{P}}
\end{array}\right\} \\
& 0 \leq \Psi, \Gamma_{\mathrm{A}}, \Gamma_{\mathrm{P}}, \rho, \Phi_{\mathrm{A}} \leq 1
\end{aligned}
$$

Where:

$\Psi=$ Probability of agency conflict occurrence or presence

$\Gamma_{\mathrm{A}}=$ Economic rationality exercised by the agent in stewarding the principal's investments

$\Gamma_{\mathrm{p}}=$ Economic rationality required by the principal in stewarding the principal's investments

$\Phi_{\mathrm{A}}=$ Agent's economic rationality upper bound estimated by entropy-q rationality model [8]

$\rho=$ Integrity coefficient estimated by Global Ethics and Integrity Benchmarks [11].

\section{Positive and negative agency conflict}

Negative agency conflict occurs when the agent's operational financial decision making rationality is less than the principal's desired rationality for management of the principal's investments. Given the argument that every rationality level relates to a given return on assets, negative agency conflict can only result to a lower than the principal's desired return on her investments. On the other hand, a positive agency conflict arises when the principal's desired rationality is greater than the one their agent has engaged. This means that the probability of occurrence of the conflict depends on the prevailing difference between the two rationalities as a proportion of the total possible difference ( $\Gamma \mathrm{A}$ ГР)/ (ФА-ГР). Table 4 shows the effect of various such proportions on corporate integrity of values $0.6,0.9$ and 0.3 [31-33].

From Figure 1, it is clear that the maximum likelihood of agency conflict occurrence is 1 less the corporate integrity $(1-\rho)$, so that 


\begin{tabular}{|c|c|c|c|c|c|c|c|c|}
\hline (ГА-ГР)/(ФА-ГР) & Integrity ( $\rho)$ & $1-\rho$ & (ГА-ГР)/(ФА-ГР) & $\Psi$ for $\rho=0.6$ & (ГА-ГР)/(ФА-ГР) & $\Psi$ for $\rho=0.9$ & (ГА-ГР)/(ФА-ГР) & $\Psi$ for $\rho=0.3$ \\
\hline 0.000 & 0.6 & 0.4 & 0.000 & 0.000 & 0.000 & 0.000 & 0.000 & 0.00 \\
\hline 0.083 & 0.6 & 0.4 & 0.083 & 0.033 & 0.083 & 0.008 & 0.083 & 0.05 \\
\hline 0.167 & 0.6 & 0.4 & 0.167 & 0.067 & 0.167 & 0.017 & 0.167 & 0.10 \\
\hline 0.250 & 0.6 & 0.4 & 0.250 & 0.100 & 0.250 & 0.025 & 0.250 & 0.15 \\
\hline 0.333 & 0.6 & 0.4 & 0.333 & 0.133 & 0.333 & 0.033 & 0.333 & 0.20 \\
\hline 0.417 & 0.6 & 0.4 & 0.417 & 0.167 & 0.417 & 0.042 & 0.417 & 0.25 \\
\hline 0.500 & 0.6 & 0.4 & 0.500 & 0.200 & 0.500 & 0.050 & 0.500 & 0.30 \\
\hline 0.583 & 0.6 & 0.4 & 0.583 & 0.233 & 0.583 & 0.058 & 0.583 & 0.35 \\
\hline 0.667 & 0.6 & 0.4 & 0.667 & 0.267 & 0.667 & 0.067 & 0.667 & 0.40 \\
\hline 0.750 & 0.6 & 0.4 & 0.750 & 0.300 & 0.750 & 0.075 & 0.750 & 0.45 \\
\hline 0.833 & 0.6 & 0.4 & 0.833 & 0.333 & 0.833 & 0.083 & 0.833 & 0.50 \\
\hline 0.917 & 0.6 & 0.4 & 0.917 & 0.367 & 0.917 & 0.092 & 0.917 & 0.55 \\
\hline 1.000 & 0.6 & 0.4 & 1.000 & 0.400 & 1.000 & 0.100 & 1.000 & 0.60 \\
\hline
\end{tabular}

Table 4: Proportion of exercised out of total rationality margin and corporate integrity.

Agency Conflict Discriminant \& Corporate integrity

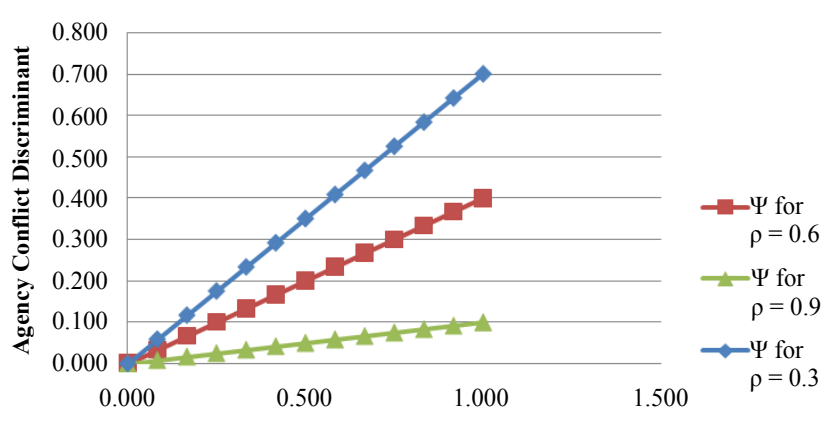

Operational /total achievablerationality margin

Figure 1: Agency conflict discriminant and various corporate integrity levels.

the higher the integrity, the lower the probability of agency conflict occurring. Using the formula given a corporate integrity of $60 \%$, the agency conflict discriminant for Stima union may be calculated thus:

$(68.51 \%-61.59 \%)(100 \%-60 \%) /(75 \%-61.59 \%)=0.2064$, interpreted to mean that there is approximately 0.2 probability that a positive agency conflict either exists or will arise between Stima union management and its members. A lower corporate integrity index of say 0.3 would result to a discriminant of 0.3612 .

Discriminants for Unitas and Mwalimu National unions are unity (certain), since $(Г А-Г Р)<0$. For this reason, a negative agency conflict can only have a discriminant value of unity. From this discussion, it can be inferred that it is very difficult to attain a positive agency conflict discriminant of unity. This would mean two things happening. One, that the agent will be exercising no integrity at all. Secondly, the agent needs to be operating at the maximum possible rationality level. Surely, for these two events to happen simultaneously, it is should be a rare occurrence. Overall, the agency conflict discriminant for the Credit union sector is unity. This should worry the regulatory authorities greatly. It should be expected that in the long run, migration from Unitas and Mwalimu National unions to Stima union or other unions with lower positive discriminants will be observed (Figure 1).

\section{Severity of certain negative agency conflict}

In the case of Unitas and Mwalimu national members, the agent's rationality level is lower than the principal's. This would represent a case where agency conflict certainly exists if and only if the principal's rationality level given is the desired one by the principal for purposes of managing her investments. If such an assumption is made, then the size of the negative difference (ГА-ГР) would represent severity of the agency. This is to say that severity is measured in rationality units while agency conflict discriminant is measured by the probability of presence or occurrence of the conflict. From Table 3, the effects of negative agency conflict can be devastating in the long run. Within 10 years, Mwalimu National management has only managed to turn the members' 4.026 times. Yet, members themselves who are actually employed have turned their wealth 6.19 times. In another 10 years (20years), members will have turned their wealth 38 times while the stewards will have turned it 16.2 times (less than half as much). But the upper limit of the steward is $73 \%$ while that of the member is $70 \%$. Is it worth depositing savings with the steward? Unless for sentimental reasons. Likewise, in 30 years, the number of times Unitas union management will have turned the members wealth will be half that of the member. This underscores the importance of comparison of the economic rationality of the agent to that of the principal. It is easier to deal with positive agency conflict than negative for at least, contention will be about disclosure not ability (Appendix A).

\section{Conclusion}

For a long time, there has not been a measure of agency conflict, whether for credit unions or for profit organizations. Financial system regulators have depended solely on quantitative financial statement interpretation. The downside being, that the wishes of the principal are usually not factored in the equation; the capacity of the agent to create wealth for the agent does not reflect in financial statements, nor does integrity. It is possible for an entity to secure clean audited accounts without having committed any fraud, but operating sub-optimally from the principal's lens. Required return by the principal depends on the staircase they are in the social-economic ladder. It is noteworthy that the principal's objectives are not only a factor of proper financial statements, but also a result of the cognitive and affective factors all of which come to play to determine her consumption, investment and savings habits, the quality of which was measured by economic rationality in this study. The proposed agency conflict discriminant as a by-product of entropy-q rationality model combines the principalagent behavioural aspects and financial accounting to obtain a comprehensive index that financial institutions regulators may use in monitoring performance of not just credit unions, but also business firms in general.

\section{Notes to Appendix A:}

1. Column (4) is a transformation of column (4) of Table 4 to obtain parameter delta using the equation 
Citation: Kirika SK (2017) By-product Extraction of a Rationality-based Agency Conflict Index from Selected Credit Unions in Kenya: Introducing the Agency Conflict Discriminant. J Bus Fin Aff 6: 279. doi: 10.4172/2167-0234.1000279

Page 6 of 6

$\delta=0.69-\{\operatorname{LOT}(\mathrm{R}) / 24\} * 0.08, \quad$ for the equation: $p_{S}=\frac{p_{O}{ }^{\delta}}{\left\{p_{o}{ }^{\delta}+\left(1-p_{o}\right)^{\delta}\right\}^{1 / \delta}}$ where $p_{\mathrm{o}}$ and $p_{\mathrm{s}}$ are objective and subjective probabilities respectively.

2. Columns (5) to (12) with the exclusion of column (6), indicate transformed subjective probabilities into objective probabilities;

3. Column (6) indicates financial decision making rationality using objective posterior probabilities (2015).

Financial decision making rationality $=\operatorname{Pr}[\operatorname{Rat}=1](1)+\operatorname{Pr}[$ Rat $=0]$ (0) e.g. for Mwalimu, $0.9808(1)+(1-0.9808)(0)=0.9808$.

4. All other columns remain the same as in Appendix A.

\section{References}

1. Smith $A$ (1937) The wealth of nations (1776).

2. Eisenhardt KM (1989) Agency theory: An assessment and review. Academy of management review 14: 57-74

3. Bendickson J, Muldoon J, Liguori E, Davis PE (2016) Agency theory: the times, they are a- changing`. Management Decision 54: 174-193.

4. Li X, Wu Z (2008) Reputation entrenchment or risk minimization? Early stop and investor- manager agency conflict in fund management. The Journal of Risk Finance 9: 125-150.

5. Anderson E (1985) The salesperson as outside agent of employee: A transaction cost analysis. Marketing Science 4: 234-254.

6. Abor J (2008) Determinants of the capital structure of Ghanaian firms (No. RP_176). Nairobi: African Economic Research Consortium.

7. Simon HA (1996) The sciences of the artificial. MIT press.

8. Kirika SK (2016) Determinants of Financial Decision Making Rationality in Deposit-taking Cooperatives in Kenya.

9. Cho CC, $\mathrm{Wu} \mathrm{CH}$ (2014) Role of auditor in agency conflict and corporate governance: empirical analyses of Taiwanese firms. Chinese Management Studies 8: 333-353.

10. Tversky A, Kahneman D (1992) Advances in prospect theory: Cumulative representation of uncertainty. Journal of Risk and uncertainty 5: 297-323.

11. Dubinsky JE, Richter A (2015) The global ethics \& integrity benchmarks. The Carnegie Council.

12. Hansen K (2004) Measuring performance at trade shows: scale development and validation. Journal of Business Research 57: 1-13.

13. Newell SJ, Goldsmith RE (2001) The development of a scale to measure perceived corporate credibility. Journal of Business Research 52: 235-247.

14. Churchill GA (1979) A paradigm for developing better measures of marketing constructs. Journal of Marketing Research 16: 64-73.
15. Tan JCK, Lee R (2015) An agency theory scale for financial services. Journal of Services Marketing 29: 393-405.

16. Brigham EF, Ehrhardt MC (2013) Financial management: Theory \& practice. Cengage Learning.

17. Hamman JR, Loewenstein G, Weber RA (2010) Self-interest through delegation: An additional rationale for the principal-agent relationship. The American Economic Review 100: 1826-1846.

18. Jones BD (1999) Bounded rationality. Annual Review of Political Science 2 297-321.

19. Manktelow K (2012) Thinking and reasoning: An introduction to the psychology of reason, judgment and decision making. Psychology Press.

20. Kalantari B (2010) Herbert A. Simon on making decisions: enduring insights and bounded rationality. Journal of Management History 16: 509-520.

21. Gonzalez R, Wu G (1999) On the shape of the probability weighting function Cognitive psychology 38: 129-166.

22. Abdellaoui M (2000) Parameter-free elicitation of utility and probability weighting functions. Management Science 46: 1497-1512.

23. Bruhin A, Fehr $\square$ Duda H, Epper T (2010) Risk and rationality: Uncovering heterogeneity in probability distortion. Econometrica 78: 1375-1412.

24. Wasiuzzaman S, Sahafzadeh I, Nejad RN (2015) Prospect theory, industry characteristics and earnings management: A study of Malaysian industries. Review of Accounting and Finance 14: 324-347.

25. Chin WW (1998) The partial least squares approach to structural equation modelling. Modern Methods for Business Research 295: 295-336.

26. Sarstedt M, Ringle CM, Henseler J, Hair JF (2014) On the emancipation of PLS-SEM: A commentary on Rigdon. Long Range Planning 47: 154-160.

27. Jaynes ET (1957) Information theory and statistical mechanics. Physical Review 106: 620.

28. Tricker RB, Tricker RI (2015) Corporate governance: Principles, policies, and practices. Oxford University Press, USA.

29. Guiso L, Sapienza P, Zingales $L$ (2015) The value of corporate culture. Journal of Financial Economics 117: 60-76.

30. OECD (2015) Corporate Governance and Business Integrity: A Stocktaking of Corporate practices.

31. Bhasin ML (2015) Corporate accounting fraud: A case study of Satyam Computers Limited.

32. Bonn I, Fisher J (2005) Corporate governance and business ethics: Insights from the strategic planning experience. Corporate governance: An International Review 13: 730-738.

33. SASRA (2013) SACCO Supervision Annual Report 2013, (Deposit Taking SACCOs). SACCO Societies Regulatory Authority (SASRA). 